Cadernos de Clio, Curitiba, v. 11, $\mathrm{n}^{\circ} .1,2020$

\title{
ENTRE O BONDE E A PAINEIRA: EMBATES DISCURSIVOS, FEMINILIDADES E MASCULINIDADES EM PERIÓDICOS UNIVERSITÁRIOS (1948-1960)
}

\section{BETWEEN “O BONDE” AND “A PAINEIRA": DISCURSIVE CLASHES, FEMININITY AND MASCULINITY MODELS IN ACADEMIC NEWSPAPERS (1948-1960)}

Arthur Lopes dos Reis ${ }^{1}$

Resumo: Este trabalho analisa os embates discursivos entre as estudantes do curso de Economia Doméstica e os estudantes dos cursos de Agronomia e Veterinária, na década de 1950. Utilizamos dois periódicos organizados por esses estudantes, A Paineira e $O$ Bonde, o primeiro majoritariamente feminino e o outro masculino. Partimos do conceito da estrutura de poder proposta por Michel Foucault e do pensamento acerca dos atos performativos e da constituição da categoria gênero elaborado por Judith Butler. Buscamos entender de que maneira a disputa binária instituída entre masculinidades e feminilidades foi um fator estruturante e como essas categorias foram definidas nas relações entre os dois grupos, formando identidades que se construíram na vivência dentro do meio acadêmico e social da Universidade Rural do Estado de Minas Gerais, atual UFV.

Palavras-chave: Embates discursivos; periódicos universitários; gênero; cursos superiores; machismos.

Abstract: This work aims to analyze the discursive clashes between the students of the Home Economics course and the students of the Agronomy and Veterinary courses, in the 1950's. We used two newspapers, organized

\footnotetext{
${ }^{1}$ Graduando em História pela Universidade Federal de Viçosa, na qual ingressou em 2018. Atualmente é membro do Laboratório de Estudos de Gênero e Ensino de História (LEGEH - UFV), sob orientação da Prof ${ }^{\mathrm{a}}$. Dr ${ }^{\mathrm{a}}$. Gilmária Salviano Ramos. Email para contato: arthur.1.lopes@ufv.br. Endereço para o Currículo Lattes: http://lattes.cnpq.br/5164916618068917.
} 
by these students, $A$ Paineira and $O$ Bonde, mostly female and male bulletins, respectively. We start from the concept of the power structure proposed by Michel Foucault and from the theory of performative acts and the constitution of the gender category elaborated by Judith Butler. We seek to understand how the binary dispute set between masculinities and femininities was a structuring factor and how they were defined in the relations between the two groups, forming identities that were built in the experience within the academic and social environments of the Rural University of the State of Minas Gerais, currently known as UFV.

Keywords: Discursive clashes; academic newspapers; gender; degree courses; sexisms.

\section{Introdução}

“\#NÓSRESISTIREMOS”. Por vários locais da Universidade Federal de Viçosa (UFV) se podem ver adesivos que estampam esta frase junto a uma fênix vermelha. Representa-se a luta do corpo discente do curso de Economia Doméstica pela continuidade dele, que teve sua existência ameaçada no ano de 2016, em um tentativa, não inédita, de excluir os estudos domésticos dos cursos oferecidos de forma pública e gratuita.

O curso de Economia Doméstica desde seu início lutou por sua existência e afirmação dentro do corpo acadêmico Ufviano. No presente artigo, remetemos ao momento de fundação do curso na UFV, em meados do século XX. Neste contexto pode-se destacar a dupla jornada por que passavam as alunas: mais do que uma luta pela existência de um curso universitário, tratava-se da luta pela inserção de mulheres no meio acadêmico e na produção de ciência. ${ }^{2}$

${ }^{2}$ Para uma análise da criação e da história do curso de Economia Doméstica na Universidade Federal de Viçosa, consultar a tese do Professor Fábio Simão (2016): 
Neste sentido, o movimento de busca por validação dentro da academia é, além de uma luta institucionalizada, um debate que percorre as noções de masculinidade e feminilidade e que reflete sobre seus papéis, deveres e comportamentos no meio social.

Intrínsecos à vivência social humana, os níveis de subjetividade e complexidade, dentro das relações de poder que constituem e moldam a organização da sociedade, são conceituados de várias formas durante nossa existência. Geram-se certos conceitos que, em boa parte das vezes, são considerados gerais e universais, criando modos de enxergar o mundo limitados a nossa linguagem, que parte não só de nossa individualidade, mas também de mecanismos sociais que moldam nossas percepções e identificações. Assim foram consideradas por um longo tempo as categorias que serão analisadas neste trabalho.

Feminilidade e masculinidade, como todos os discursos que circundam esses conceitos, são e devem ser lidos sob um olhar histórico, conforme defendido por este e outros trabalhos, que se propõem a construir algum conhecimento sobre a realidade. Embora residam dentro de um campo de saber que possui regras e métodos, são transmitidos e construídos através de escritos, os quais partem de um ponto por sua vez insuficiente para abarcar toda a complexidade do real à medida que está imerso em redes sociais de poder e significação.

Ser mulher, "uma missão": A escola superior de ciências domésticas, domesticidade, discurso e representações de gênero (1948-1992). 
É claro, o modo como estes conceitos se estruturam em nosso modo de pensar atual parece se aproximar muito mais de uma realidade tangível, embora fragmentada, que nos passa certa ilusão de objetividade em sua própria subjetividade. No entanto, tal esfera do real não deve ser descartada como uma habitante da colcha de retalhos chamada linguagem, ocorrendo o mesmo com todas as suas características guiadas por essas relações, situadas entre poder/discurso/saber, como nos aponta Michel Foucault ao longo de seus vários escritos.

Desse modo, este trabalho se estrutura na compreensão de que todos os saberes contidos aqui são visões de quem os produz, podendo não corresponder ao que significaram as vivências das pessoas, ou melhor, dos grupos aqui citados. Apenas a visão interpretativa daquele que, com sua mente e escrita, coloca em contingência os corpos do passado, quase os coloniza, retirando o que para si é provido de sentido. Assim, para prosseguirmos com nossa análise, devemos traçar um breve apontamento a respeito dos principais referenciais teóricos, fontes e pesquisa.

Pode-se encarar o ambiente educacional - seja em nível fundamental, médio ou superior - como um espaço de construção e desconstrução de ideias, de modos de ser e de individualidades conflitantes. Desta maneira, deve-se enxergar esses lugares como transformadores e constituintes de sujeitos e experiências que nos dizem muito sobre determinadas épocas e lugares, suas relações de poder e formações de subjetividades.

Nosso trabalho consiste em uma análise sobre o modo como, dentro das relações de poder institucionais, algumas estudantes do curso de 
Economia Doméstica e alguns estudantes dos cursos de Agronomia e Veterinária enxergavam uns aos outros; como manifestavam e enxergavam seus gêneros; e, sobretudo, como a presença feminina era sentida no meio acadêmico, quase puramente masculino, não fosse a presença das turmas de Economia Doméstica e raras exceções nos demais cursos.

Para isso, usaremos os periódicos A Paineira e $O B B_{0} e^{3}$, sendo um feminino e um masculino. Tais publicações devem ser vistas como espaços de discussão e de voz das alunas e dos alunos em relação ao meio universitário, sobre o mundo e sobre si mesmos. Falaremos mais sobre os periódicos adiante. O material analisado compreende do ano de 1956 a 1960, datas que marcam respectivamente, a primeira edição d'A Paineira e seu último volume. Vale ressaltar que o periódico $O$ Bonde inicia suas publicações em 1945 e permanece até 1963. No entanto, como se pode inferir, nestes períodos perdemos o fator principal que acompanhará esse artigo: a relação e a discussão entre os dois jornais. Além disso, a escolha das fontes determinou a dimensão geográfica da pesquisa: a cidade de Viçosa, especialmente a UREMG/ESAV ${ }^{4}$.

\footnotetext{
${ }^{3}$ Boa parte das publicações se encontram disponíveis de forma online e gratuita no site Atom - UFV, que cuida da difusão da memória institucional da universidade. Para acessá-lo, visitar: http://atom.ufv.br/.

4 A Universidade Federal de Viçosa iniciou sua trajetória na década de 1920, funcionando como Escola Superior de Agricultura e Veterinária (ESAV) até o ano de 1948, quando, com a criação do curso de Economia Doméstica, passa a se chamar "Universidade Rural do Estado de Minas Gerais (UREMG)". Posteriormente, embora sendo um período de tempo não contemplado por nossas fontes, a instituição eleva-se ao título de Universidade Federal de Viçosa, em 1968.
} 
Uma referência importante neste trabalho é o conceito de relações de poder descrito por Michel Foucault (1988: 79-125), que nos ajuda a perceber e refletir sobre o caráter relacional dos embates entre as masculinidades e as feminilidades. Este autor aumenta a complexidade do nosso entendimento sobre os modos pelos quais o poder atua e se manifesta no campo social. Entende-se um poder que não possui núcleo ou polo definido, mas sim múltiplas relações de poder que são emitidas em cada ação humana.

Foucault rompe com uma tradição que entende o poder como algo puramente negativo, repressor. Entende o caráter positivo e, sobretudo, relacional do poder, de modo que não se pode fugir das relações de poder, que são multifocais e constroem o todo social em que estamos inseridos. Desta forma, depreende-se que as relações de poder estão intimamente ligadas a sua própria resistência. Desprezar este entendimento seria retirar dos indivíduos sua agência perante o mundo. Ou em outras palavras:

[...] desconhecer o caráter estritamente relacional das correlações de poder. Elas não podem existir senão em função de uma multiplicidade de pontos de resistência que representam nas relações de poder, o papel de adversário, de alvo, de apoio, de saliência que permite a preensão. Esses pontos de resistência estão presentes em toda a rede de poder. Portanto, não existe, com respeito ao poder, um lugar da grande Recusa - alma da revolta, foco de todas as rebeliões, lei pura do revolucionário. Mas sim resistências, no plural, que são casos únicos: possíveis, necessárias, improváveis, espontâneas, selvagens, solitárias, planejadas, arrastadas, violentas, irreconciliáveis, prontas ao compromisso, interessadas ou fadadas ao sacrifício; por definição, não 
podem existir a não ser no campo estratégico das relações de poder (FOUCAULT, 1988: 90).

Além disso, deve-se ressaltar a importância do pensamento de Judith Butler neste trabalho. Esta autora parte da ideia da categoria gênero como algo construído a partir das práticas que lhe dão significado. Trata-se de atribuir um caráter histórico, social e culturalmente construído a esta dimensão, para além do binarismo naturalizado, pautado em torno do sexo biológico, que geralmente ronda os conceitos de homem/mulher. Entende-se que o gênero nem sempre se constituiu de maneira coerente ou consistente nos diferentes contextos históricos. Assim, o gênero não

é de modo algum uma identidade estável nem lócus de agência do qual procederiam a diferentes atos; ele é, pelo contrário, uma identidade constituída de forma tênue no tempo - uma identidade instituída por meio de uma repetição estilizada de atos (BUTLER, 2018: 3).

Neste sentido, Butler evidencia o caráter performativo da identidade de gênero. Para a autora, devemos entender esta forma de constituição como a "maneira cotidiana por meio da qual gestos corporais, movimentos e encenações de todos os tipos constituem a ilusão de um 'eu' generificado permanente" (BUTLER, 2018: 3), sendo naturalizado pelos sujeitos, mesmo que de forma ilusória.

Ainda sobre o fator interno e da percepção dos sujeitos ao gênero como algo dado e natural, a autora conclui, de maneira mais clara: 
A distinção de gênero faz parte da "humanização" dos indivíduos dentro da cultura contemporânea; assim, quem não efetua a sua distinção de gênero de modo adequado é regularmente punido. Como não existe uma "essência" que o gênero expresse ou externalize, nem um objetivo ideal ao qual aspire; como o gênero não é um fato, os vários atos de gênero criam a ideia de gênero; sem esses atos, não haveria gênero. $\mathrm{O}$ gênero, portanto, é uma construção que oculta regularmente a sua própria gênese. $\mathrm{O}$ consentimento tácito coletivo quanto a representar, produzir e sustentar gêneros polarizados e distintos como ficções culturais é obscurecido pela credibilidade concedida à sua própria produção. Os autores do gênero ficam encantados com suas próprias ficções; desse modo, a própria construção faz com que se acredite que ela é necessária e natural. As possibilidades históricas materializadas em vários estilos de corpo nada mais são do que essas ficções culturais reguladas por punições, alternadamente corporificadas e disfarçadas sob coerção (BUTLER, 2018: 6).

Deste modo, o fator "humanizante" em torno da categoria binária de gênero evoca um fator punitivo nos que desviam deste lugar "natural". Em certo sentido, as alunas da ESCD podem ser entendidas como desviantes e, ao mesmo tempo, como fundadoras de novas formas, ou melhor, de novos lugares que o seu gênero pôde ocupar, o que não significa, é claro, que este processo de "fundação" tenha sido linear e passivo por parte do corpo hegemônico que preenchia o ambiente universitário naquele período.

Assim, devemos levantar alguns pontos sobre o contexto em que essas vivências se dão e fazer breves apontamentos sobre o modo como as/os estudantes interagiam entre si, suas contradições e entendimentos de 
mundo, que, embora conflitantes e plurais, se enquadram em certo imaginário coletivo formado em suas relações acadêmicas e cotidianas. Tais relações são, em um plano maior, dicotômicas, binárias e bem delimitadas no que diz respeito à forma pela qual o gênero foi construído/percebido por estas pessoas através de performances discursivas, manifestas nas páginas de seus jornais estudantis.

\section{Os periódicos universitários: projetos e funcionalidade}

Quando de sua criação no ano de 1926, como dissemos anteriormente, a Escola Superior de Agricultura e Veterinária teve seu corpo discente formado exclusivamente por homens, aspecto mantido até finais da década de 1940, quando observamos as primeiras alunas da instituição. Essas foram incorporadas aos cursos de Agronomia e Veterinária. Em 1948, tem-se a criação do curso de Economia Doméstica, que provoca o alargamento da presença feminina no campus (BARDUNI FILHO; FERRARI; LOPES, 2017: 20).

Os primeiros personagens deste artigo começam a aparecer três anos antes, em setembro de 1945. Neste período se tem a primeira edição do encarte $O$ Bonde. Em seu primeiro artigo nos são apresentados o jornal e seus objetivos, que podem ser resumidos neste trecho:

Diversos são os motivos que nos mobilizaram para a fundação deste semanário. Objetivamos de início, que ele fosse uma tribuna livre para todos os Esavianos exporem os seus pontos de vista, quaisquer que fossem. Que nestas colunas todos encontrassem um campo aberto para os debates dos problemas 
máximos do mundo, do nosso país e da Esav ( $O$ Bonde, Edição 01: 1).

Isso explica o caráter subjetivo e informal denotado em suas páginas, em que se podem encontrar falas sobre os mais diversos assuntos, escritas por vários alunos com opiniões e pensamentos diferentes. Contudo, eles seguiam certos padrões, como de linguagem, de escrita e de temas abordados, que estão impregnados pelo imaginário coletivo que compartilhavam, provocado pela vivência coletiva acadêmica e social. ${ }^{5}$ Fica claro de qual local partem os posicionamentos dos que escrevem para $O$ Bonde. Trata-se de um jornal plural, no sentido de ser feito e escrito por diversas pessoas, embora singular no que se refere a quem podia escrever, isto é, o grupo de alunos da ESAV.

Podemos apontar o caráter "inquisitorial", de vigília/observação/denúncia, por parte dos que escreviam no periódico. Denunciam-se atitudes de professores, de colegas, da reitoria da universidade. Pode-se citar a coluna de nome "Fatos e Boatos", que era utilizada de forma humorística para criticar a instituição e outros membros daquele círculo social. Como exemplo, destacamos este trecho: "que a guerra não terminou é boato, mas que na Escola o racionamento de pão continua, é fato" ( $O$ Bonde, Edição 07: 3).

\footnotetext{
${ }^{5} \mathrm{Na}$ ESAV existia a intenção de criar um grupo coeso, uma irmandade que giraria em torno de certos ideais. Para uma análise mais detalhada indico o trabalho de Eduardo Simonini Lopes. Segundo este autor ser Esaviano “... correspondia ao comprometimento com o cultivo de uma postura 'correta' em direção aos valores de progresso, cooperação, honestidade, higiene, fazer prático/científico..." (LOPES, 2014: 254-255).
} 
Posteriormente se comenta também sobre as alunas da Economia Doméstica. Essas críticas, que podem ser observadas em boa parte das edições de $O$ Bonde, tratam sempre de colocar o jornal e seus autores em posição de superioridade. Falaremos mais sobre isso adiante.

Por outro lado, temos o periódico A Paineira. Esta publicação, de certo modo, possuía objetivos semelhantes com os de $O$ Bonde, como a finalidade de dar espaço às alunas para exporem suas ideias e opiniões sobre o mundo ao seu redor, além buscar

por em relevo, por meio de críticas construtivas, os fatos curiosos de nosso ambiente estudantil, que muitas vezes passam despercebidos, em prejuízo de nossas futuras colegas, que não se beneficiariam de nossa experiência (A Paineira, Edição 03: 1).

Evidencia-se o caráter pioneiro deste grupo. Afinal, essas alunas são as primeiras mulheres a ocupar um espaço até então lido como masculino e considerado distante de um lugar "natural" das mulheres.

Deve-se levar em conta o descrédito em relação à iniciativa de produção de $A$ Paineira por parte dos produtores d' $O$ Bonde. As edições a que temos acesso e que foram utilizadas neste artigo tratam-se de uma segunda tentativa de publicação d'A Paineira. Anteriormente, outro grupo de alunas tentou produzir um periódico para o curso de Economia Doméstica sem êxito, ou melhor, sem continuidade, publicando apenas duas edições. 
Após o "fracasso" das primeiras edições do jornal, a nova direção tem um novo e dispendioso caminho: afirmar-se como curso e, neste caso, enquanto capaz de manter um jornal. Podemos perceber certa recepção hostil a esta iniciativa nas páginas de $O$ Bonde. A opinião de um aluno desconhecido que lá escreve, usando um espaço aberto para manifestações discentes, diz: "Agora A Paineira sai! Ah! Sai. Vai sair todo dia... de ônibus! Acabou o mundo!” (O Bonde, Edição 175: 2).

$\mathrm{O}$ lado feminino do conflito não desanimou perante tal situação. $\mathrm{O}$ que vemos por parte das alunas é uma posição de confronto e resistência. Podemos perceber as diferenças na produção do discurso, um que subalterniza e questiona e outro que se impõe, se eleva e busca afirmar suas capacidades. As alunas da ESCD entendem a situação e apresentam sua visão, segundo a qual a direção anterior não fracassou. Conforme aponta Ignez Martins ${ }^{6}$ :

Quando, pela primeira vez, encaramos um problema, somos levados a um terrível pessimismo, no que diz respeito à sua solução. Tal acontece conosco, que ora iniciamos como "plumitivas", esta missão de apresentar à nossa universidade, um pouco do que somos e do que pretendíamos. Atividade tentada por antigas alunas, com relativo bom êxito, já apareceram dois números da Paineira (A Paineira, Edição 03: $1)$.

${ }^{6}$ Uma das idealizadoras da nova iniciativa de construção da A Paineira atua como diretora do jornal até, mais ou menos, sua edição de número 07. Não podemos afirmar com base nas fontes, ao certo, quando esta deixa a direção, nem por quais motivos, tendo em vista que as edições 08 e 09 não sobreviveram ao tempo e que a de número 10 já aparece com nova direção. 
Ao longo das edições, as autoras nos apresentam suas visões sobre uma ampla variedade de assuntos, que vão dos esportes universitários às festas, das apresentações de trabalhos às reformas e construções na universidade. Na maioria dos artigos, expõe-se o que gostaram ou não, mas sempre tecendo críticas.

Um fato interessante, e que se deve levar em consideração, é que para além das diferenças, as semelhanças na forma de escrita, na organização dos jornais, nos lugares frequentados e em vários outros aspectos demonstram que essa separação que não/pouco se dava geograficamente, ocorre ainda menos no campo intelectual, não fossem os conhecimentos adquiridos nos cursos, que obviamente divergiam em aplicação e conteúdo.

Descrito esse breve contexto, podemos passar ao segundo momento deste artigo, em que iremos analisar o modo como os dois grupos construíram discursos sobre o mundo e sobre o outro. Formando embates que nos mostram como são entendidas suas identidades, seus respectivos papéis "naturais" e, em um sentido mais amplo, certa essência do que significaram as categorias homem e mulher, os materiais possibilitam que procuremos perceber a crítica a esse entendimento limitante e sua possível ruptura.

\section{Embates discursivos e pela verdade: ESCD X ESAV}


Nosso último tópico se distribuirá em duas partes. A primeira analisa e relaciona $A$ Paineira e $O$ Bonde, restringindo nossa busca às falas de um grupo que dizem respeito ao outro, não necessariamente procurando identificar conflitos, mas qualquer menção que nos mostre uma construção de identidade de gênero expressa através do imbricamento relacional. Em segundo lugar, olharemos para o percurso que as estudantes da ESCD fazem para buscar/impor sua aceitação dentro do meio acadêmico, suas opiniões sobre o curso e sobre qual deveria ser o papel da mulher.

Podemos perceber como o jornal A Paineira se posiciona de maneira nada sutil perante os problemas da sociedade e da juventude. Fazem alusões que podem ser consideradas, após a leitura d' $O$ Bonde, claramente críticas aos modos masculinos. Um bom exemplo encontra-se no texto "A juventude Coca-Cola”, escrito pela diretora do jornal, Ignez Martins, que ao tratar sobre a geração jovem da época e suas posturas - em suas palavras, um conjunto de "bonecos na mão da vaidade e do artificialismo" ( $A$ Paineira, Edição 05: 1-2) - não deixa de proferir críticas aos rapazes da ESAV.

O texto, escrito de forma erudita e crítica, censura o uso de gírias e palavras de línguas estrangeiras. Podemos perceber críticas que são direcionadas não só à "juventude” brasileira, como também um perceptível ato de censura aos rapazes da ESAV:

o campo para o abuso de palavras estrangeiras, quando em nosso vocabulário é bastante farto, até criações como "kar"",

\footnotetext{
${ }^{7}$ Em português, "elegante".
} 
provenientes da imaginação do Sr. Ibrahim Sued, encontram adepto, que por certo ficariam humilhados se desconhecessem o significado de tal palavra (cuja tradução até hoje não foi encontrada nas línguas civilizadas) (A Paineira, Edição 05: 1).

Este trecho passaria despercebido, não fosse o fato de que nos textos do jornal $O$ Bonde, alguns dos escritos, carregam alto grau de estrangeirismos e gírias, como apontado por Martins, a exemplo de: "a amplitude de variação foi grande devido alguns acontecimentos muito kar e outros very grossos" (O Bonde, Edição 175: 3).

Neste e em outros momentos podemos ver uma vontade de mudança por parte do grupo feminino, que critica o grupo masculino e o seu respectivo modo juvenil de agir. Pela leitura das fontes, o que se constata é a exigência feminina por um desempenho masculino mais polido e por uma lógica de organização que emancipe ou pelo menos melhore a vivência das mulheres. Pode-se observar esta ideia claramente em um texto escrito por uma aluna que se identifica como "Minerva", chamado "Coeducação", no qual a autora reflete sobre a "educação de pessoas de sexos diferentes, em comum" (A Paineira, Edição 05: 3). Ela diz:

Para a coeducação numa escola, por exemplo, de nível superior, já se pressupõe que os alunos tenham certa formação moral que lhe permitirá ter atitudes convenientes com sua idade. Estaremos contribuindo para a coeducação promovendo o conhecimento necessário entre moças e rapazes através da amizade, do convívio diário, e não por meio exclusivo do namoro, como muitos de nossos jovens julgam. [...] Como pessoas de sexos diferentes, homens e mulheres pensam e julgam de maneira diferente, e apesar de propalar a fraqueza 
da mulher, esta tem vontade própria e almeja a liberdade de seus pensamentos, tanto quanto os homens desejam a de seus atos (A Paineira, Edição 05: 4).

Outra situação em que fica clara a demanda de uma melhor educação dos homens é um texto de uma aluna identificada como "Sayonara", no qual, ao falar sobre as festas organizadas pelos alunos da Agronomia, repreende alguns comportamentos assediadores masculinos:

às vezes aparecem senhores que se esquecem dos tempos modernos, onde a moça aprecia muito mais uma conversa amigável, do que os corriqueiros elogios à queima roupa, tão em desuso para qualquer mentalidade evoluída (A Paineira, Edição 03: 3).

É interessante notar o ímpeto crítico de Sayonara. Em outra edição, falando sobre o mesmo tema, censura um rapaz da seguinte forma: "a única nota chocante da festa é certo rapaz que até hoje não conhece o que é senso de humor, e não só ali, como em outros lugares, tem demonstrado sua enorme falta de ética" (A Paineira, Edição 04: 3).

Esta fala é um tiro que acerta o alvo. Na edição seguinte de $O$ Bonde um rapaz que se identifica como "Strogof", escreve um artigo intitulado “Ética e senso de humor", em réplica ao artigo de Sayonara. Neste texto ele se defende e ataca a aluna de forma clara e agressiva, o que é acentuado pela forma culta e científica de escrita, conforme exemplificado pela frase inicial do texto: 
Sayonara, um pseudônimo digno de uma pessoa deficiente em fosfatídeos que carecem de colina. [...] Em sua fuliginosa crônica destas quatro folhas mimeografadas que muitos cognominam de "A Paineira", tentou em vão fubecar a minha pessoa, que por falta de sorte de sua parte é invulnerável a ataques de microrganismos patológicos, principalmente aos da família SAYNAREAE. Sua inexatidão ao empregar termos como ética e humor deixa bem patente a sua iconoclastia quanto aos princípios básicos de nossa linguagem. Qualquer membro da academia de letras, por mais néscio que seja, classificaria seus artigos como pútridos e tudo faria para sepultá-los, fazendo veemente apelo aos germes telúricos da decência para que exterminassem por completo esse mal, que por todos sabido, insensível a qualquer medicamento [...] $(O$ Bonde, Edição 175: 3).

Uma característica marcante dos textos masculinos que se dedicam a criticar as moças é o alto grau de erudição, uso de palavras científicas, e metáforas altamente bem elaboradas. Pode-se pensar sobre a causa desta prática deliberada por parte dos alunos da Agronomia de se colocarem como superiores, produzindo textos que, na sua visão, as mulheres não teriam capacidade cognitiva de ler ou escrever. Embasamos essa ideia em trechos não raros do jornal, como o fragmento acima, no qual a forma de escrita d'A Paineira é criticada.

Ao longo do texto recheado de depreciações e de dúvida à capacidade cognitiva das alunas, podemos ver o modo como estes homens se entendiam superiores, detentores de todas as possíveis verdades e discursos decorrentes de quaisquer práticas que surjam. 
Outro ponto de extrema relevância é a noção de emancipação da mulher que podemos acessar através das páginas d'A Paineira. $\mathrm{O}$ grupo de alunas da Economia Doméstica, a todo instante, nos apresentou uma forma de enxergar essa questão, que se estrutura em duas ideias: 1) o progresso da humanidade pede que a mulher tenha conhecimentos além dos que lhes eram dados normalmente. As mulheres devem assumir seu lugar, com ciência e conhecimento, a fim de guiar a pátria rumo ao progresso. E 2) a mulher, embora diferente do homem, possui as mesmas habilidades que ele. Foi-se o tempo em que uma mulher deveria apenas aprender tocar piano, cantar e ler poesia. A mulher da época (anos 1950) seria uma cientista, uma profissional a ser respeitada.

Para entender essas colocações se faz necessário um exercício de imaginar as estruturas sociais que estão por trás dessas falas. Em nossas fontes, pôde-se identificar uma estrutura semelhante que guia as opiniões de ambos os periódicos. Nota-se um forte nacionalismo, uma noção arraigada de progresso e de que novos tempos estão por vir, que se explica até mesmo pelo lugar onde estão: uma universidade pública, de ideologia utilitarista, influenciada pelos ideais estadunidenses (SIMÃO, 2016: 131-145). Esta universidade tem, desde sua origem, um forte compromisso com a economia brasileira; afinal, até os dias de hoje, uma das principais fontes de riqueza do Brasil é sua forte exportação de produtos agrícolas.

Podemos definir as dimensões da sociedade dos anos $1950 \mathrm{em}$ poucas palavras, como nacionalismo/utilitarismo/progresso, que podem representar em certa medida os valores desse grupo de alunas. Entretanto, 
não devemos ignorar o fator de unificação dessas ideias: a Economia Doméstica. Como se pode ver no seguinte trecho do artigo de Maria Lúcia Simonini, chamado "Influências das Ciências Domésticas na formação da mulher', os estudos femininos apareciam conectados a um todo maior, que é desejado para o bom funcionamento da sociedade:

De todas as responsabilidades da mulher, a maior e a mais séria, é a formação do lar. Grandes esforços e vasta soma de ideia deve a mulher dispender para manter a integridade doméstica e fazer do lar um ambiente que convenha ao esposo e aos filhos. Visando facilitar o desenvolvimento e o aperfeiçoamento dos ideais femininos, foi criada a escola superior de ciências domésticas, para fazer das mulheres verdadeiras educadoras no lar, na sociedade e no magistério. Sabemos que a sociedade de hoje exige do sexo feminino uma melhor colaboração nos vários setores da vida, a fim de valorizar o meio e combater, com armas eficientes, o egoísmo e a tendência para a desagregação da família. Cabe à mulher incentivar a caridade, a solidariedade e a justiça, levando, com a intenção que lhe é particular, à paz e à união do meio social (A Paineira, Edição 13: 1).

Como já dissemos várias vezes nesse artigo, uma das funções do jornal era dar voz às alunas e validar o lugar das Ciências Domésticas no meio acadêmico. Um campo disciplinar que estuda coisas relativas ao lar não é muito levado a sério nas nossas sociedades, nem hoje, nem naquele tempo. No entanto, podemos encontrar algumas estratégias sobre as quais essas estudantes se amparam para dar ao seu curso uma legitimidade. Suas estratégias são muito bem definidas dentro de suas argumentações, como 
tratar de trazer o debate científico para o lar, o que não era uma questão de gosto, mas de necessidade. Vemos argumentos que cuidam de "alargar" o papel das mulheres, que buscam certa emancipação, não obstante em muitos momentos delegarem a elas um papel bem definido e pouco móvel.

\section{Conclusão}

Deste modo, constatam-se dois pontos principais. Primeiramente, pode-se apontar uma visão que começou a se fragmentar naquele momento, da noção do que é ser mulher e do que é ser homem. Refletindo sobre o caráter contingente das identidades de gênero, sobre como são pensadas em diferentes épocas e sobre o fato de que estão a todo o momento sofrendo novas formas de significação e construção, podemos perceber que, no período analisado, o discurso binário e compartimentado é presente nas definições e imagens que homens e mulheres têm de si mesmos.

Pode-se enxergar o início de uma mudança no status quo essencialista, marcadamente binário e excludente. Através das páginas de $A$ Paineira, as alunas criticam os comportamentos excludentes e que buscam delimitar o espaço feminino em uma sociedade amparada sobre a hegemonia masculina. Nesse sentido, pode-se destacar o distanciamento de uma ideia segundo a qual o homem seria mais apto para desenvolver determinadas ações, como estar no meio acadêmico, exercer trabalho braçal, etc, enquanto a mulher estaria mais afeita ao trato do lar e da família, de maneira pouco crítica e bastante subserviente. 
Em nosso texto, enxergamos um modo de agir que começa a ser formulado pela presença e ação do grupo feminino que ingressa na universidade. Notam-se algumas resistências por parte dos alunos homens da ESAV, rebatidas pelo grupo feminino.

Deste modo, observa-se que a presença feminina, a criação do curso e a busca por afirmação das alunas criam um momento de tensão, em que são postas à prova as categorias que pensamos neste trabalho. Assim, vamos de encontro às ideias de uma consequência punitiva para os que desviam do esperado em sua performance de gênero e para o caráter contingente e performático destas categorias. Muito há de se enfrentar, como enfrentaram as alunas da ESCD, quando se deseja romper com práticas arraigadas no imaginário coletivo em busca de liberdade.

\section{Referências}

BUTLER, Judith. Problemas de Gênero: Feminismos e subversão da identidade. Rio de Janeiro: Civilização Brasileira, 2003.

- Atos performativos e constituição de gênero: um ensaio sobre fenomenologia e teoria feminista. Caderno de leituras, Belo Horizonte, $\mathrm{n}$. 78, p. 1-16, 2018. Disponível em: $<$ https://chaodafeira.com/uploads/2018/06/>. Acesso em: 06 maio 2021.

CERTEAU, Michel de. A Escrita da História. Rio de Janeiro: Forense-Universitária, 1982.

BARDUNI FILHO, Jairo; FERRARI, Anderson; LOPES, Eduardo Simonini. Um jornal na fronteira: breves considerações sobre a produção de masculinidades no semanário estudantil "O Bonde”. Margens - Revista Interdisciplinar, Abaetetuba, v. 11, n. 17, p. 11-27, jul./dez. 2017. 
Disponível em: <https://www.academia.edu/35765098/>. Acesso em: 06 maio 2021.

FOUCAULT, Michel. História da sexualidade: a vontade de saber. Rio de Janeiro: Edições Graal, 1988. v. 1.

- Microfísica do poder. Organização e tradução de: Roberto Machado. Rio de Janeiro: Edições Graal, 1979.

LOPES, Eduardo Simonini. "Espírito Esaviano" e cotidiano discente na Escola Superior de Agricultura e Veterinária do estado de Minas Gerais. Cadernos de História da Educação, Uberlândia, v. 13, n. 1, p. 251-266, jan./jun. $2014 . \quad$ Disponível em: $<$ http://www.seer.ufu.br/index.php/che/article/view/28177/15548>. Acesso em: 06 maio 2021.

SCOTT, Joan Wallach. Gênero: uma categoria útil de análise histórica. Educação \& Realidade, Porto Alegre, v. 20, n. 2, p. 71-99, jul./dez. 1995.

. História das Mulheres. In: BURKE, Peter (Org.). A escrita da história: novas perspectivas. São Paulo: Ed. UNESP, 1992. p. 65-98.

SIMÃO, Fábio Luiz Rigueira. Ser mulher, "uma missão”: A escola superior de ciências domésticas, domesticidade, discurso e representações de gênero (1948-1992). 2016. 267 f. Tese (Doutorado em História) Programa de Pós-Graduação em História, Universidade Federal de Juiz de Fora, Juiz de Fora, 2016. Disponível em: <https://www2.ufjf.br/ppghistoria//files/>. Acesso em: 06 maio 2021.

Recebido em: 01/03/2021 Aceito em: 08/05/2021 